\title{
Study on the Ignition Process and Characteristics of the Nitrate Ester Plasticized Polyether Propellant
}

\author{
Xiaoting Yan $\mathbb{D}^{1},{ }^{1}$ Zhixun Xia, $^{1}$ Liya Huang, ${ }^{1}$ Likun $\mathrm{Ma},{ }^{1}$ Xudong $\mathrm{Na}\left(\mathbb{D},{ }^{1}\right.$ Yunchao Feng, \\ and Chuanbo Fang ${ }^{2}$ \\ ${ }^{1}$ College of Aerospace Science and Engineering, National University of Defense Technology, Changsha 410073, China \\ ${ }^{2}$ Qinghe Building Ding-7, Beijing 100085, China \\ Correspondence should be addressed to Xudong Na; ngvjai@126.com
}

Received 13 July 2020; Revised 22 August 2020; Accepted 10 September 2020; Published 22 September 2020

Academic Editor: Li Yan

Copyright (c) 2020 Xiaoting Yan et al. This is an open access article distributed under the Creative Commons Attribution License, which permits unrestricted use, distribution, and reproduction in any medium, provided the original work is properly cited.

\begin{abstract}
In this study, a $\mathrm{CO}_{2}$ laser ignition experimental system was built to study the ignition process and characteristics of the Nitrate Ester Plasticized Polyether (NEPE) propellant. The effect of the energy density, ingredients, and the grain size distribution of the propellant on the ignition process was investigated using a $\mathrm{CO}_{2}$ laser igniter, a high-speed camera, and a tungsten-rhenium thermocouple. Four types of NEPE propellants were tested under different laser heat fluxes, and the ignition delay time, the ignition temperature, and the ignition energy were obtained. Experimental results show that the ignition process of the NEPE propellant can be divided into three stages, namely the first-gasification stage, the first-flame stage, and the ignition delay stage. When the energy density is lower than the ignition energy threshold, the ignition process cannot be achieved even under continuous energy loading. The increase of the energy density can lead to the decrease of the ignition delay time but has little effect on the ignition temperature. The ingredients and grain size distribution have great effects on both the ignition delay time and the ignition temperature. The grain size effect of aluminum is the largest compared with that of Ammonium Perchlorate (AP) and octahydro-1,3,5,7-tetranitro-1,3,5,7-tetrazocine (HMX), while the grain size effect of AP is larger than that of HMX.
\end{abstract}

\section{Introduction}

The solid propellant is the main energy source for solid rocket motors, which makes it important to increase its specific impulse [1,2]. The Nitrate Ester Plasticized Polyether (NEPE) is a significant breakthrough during the development of highenergy solid propellants. It combines the advantages of both the composite propellant and the double-base propellant, which means that it has both high-energy and good mechanical properties [3]. NEPE propellants have the highest specific impulse among solid propellants that have been in application in the world. Its standard theoretical specific impulse can reach $2685 \mathrm{~N} \mathrm{~s} / \mathrm{kg}$ [4].

Laser ignition has been widely used in ignition studies of solid propellants and metal particles in recent years. Its advantages include the high-energy output, controllable ignition time and energy, and low external disturbance, which effectively decreases the heterogeneous effect and the heat loss during the ignition process. Besides, the laser ignition is not sensitive to environmental factors. These advantages make an intensive study possible and increase the reliability of the experimental results [5-9]. The ignition temperature, the ignition delay time, and the ignition energy are typical characterization parameters of laser ignition properties of solid propellants. Ulas and Kuo [10] studied the ignitibility of six types of solid propellants under different $\mathrm{CO}_{2}$ laser heat fluxes and chamber operating conditions. They compared first gas evolution times and first light emission times of different propellants. Ali et al. [11] plotted the delays as a function of irradiance on log-log axes. They thought that thermal diffusion and fixed surface temperature ignition criterion are likely dominant parameters governing the ignition time. Hunt et al. [12] identified the ignition time and temperature from the infection point corresponding to the thermal runaway from the thermocouple data. They also measured the ignition time using a "first-light" criterion from the high- 
speed camera data. Zanotti et al. [13] investigated the ignition step of porous Ni-Ti mixtures and found that ignition temperatures, times, and energies are strongly dependent on the heating cycle while less dependent on composition and reactant particle size. Monagheddu et al. [14] studied the different role of ignition temperature in combustion synthesis through self-propagating high-temperature synthesis (SHS) and thermal explosion (TE) mode. Medvedev et al. $[15,16]$ studied the dependence of the laser ignition energy threshold energy density on the sample density and dispersion using pulse laser and explained their results in terms of the thermal ignition theory. Demko et al. [17] measured the ignition delay time at the pressure between $3.5 \mathrm{MPa}$ and $15.5 \mathrm{MPa}$ using a $\mathrm{CO}_{2}$ laser igniter and studied the effect of novel nanoaddictive catalysts on the ignition delay time. Sivan et al. [18] studied the diode-laser ignition of pyrotechnic mixtures and investigated the ignition delay time's dependence on laser intensity, combustion temperature, and composition. Feng et al. [19] investigated the ignition and combustion of aluminum droplets using aluminum wires and a $\mathrm{CO}_{2}$ laser igniter. Ehrhardt et al. [20] studied the pyrolysis, ignition, and combustion of low-vulnerability propellants using laser. The combustion characteristics they gained include ignition delay, maximal overpressure, burning rate, and ignition energy.

Existing laser ignition research on NEPE propellants is relatively limited compared with other propellants. Li et al. [21] studied the effect of Ammonium Perchlorate (AP) in NEPE propellants on the ignition process and the effect of different factors, namely the surface area of AP, the combustion catalyst, the initial temperature, and the heat flux, on the ignition delay time using $\mathrm{CO}_{2}$ laser ignition system under the ordinary pressure. Besides, preliminary study was done on the laser ignition energy threshold of NEPE propellants. Wang et al. [22] studied the ignition process and the temperature distribution on the burning surface of NEPE propellants under the laser irradiation using an experiment system consisting of a $\mathrm{CO}_{2}$ laser igniter, a high-speed camera, and a thermal infrared imager. They found that the increase of laser heat flux results in the decrease of ignition delay time, but the influence decreases when the laser flux is higher than $6.7 \times 10^{5} \mathrm{~W} \mathrm{~m}^{-2}$. After the laser was unloaded, the surface temperature of the propellant did not drop immediately but fell in a short delay, followed by a small slow rise. The effect of laser heat flux on the ignition delay time and the dynamic response of NEPE propellants to the unloading of the laser were analyzed. Xiang et al. [23] studied the influence of oxygen content in the environment gas on the first flame position and the ignition delay time of NEPE propellants. Zhu et al. [24] examined the effect of the laser heat flux density on the ignition delay time of NEPE propellants. Li et al. [25] investigated the influence of the ambient pressure and the initial temperature on the ignition delay time.

Previous study mainly focused on the quantitative research on the laser ignition of NEPE propellants, while few attentions have been paid to the variation of the NEPE propellant surface during the ignition process. The influence of ingredients and the grain size on the ignition process are still unclear. In this paper, we performed an extensive exper-

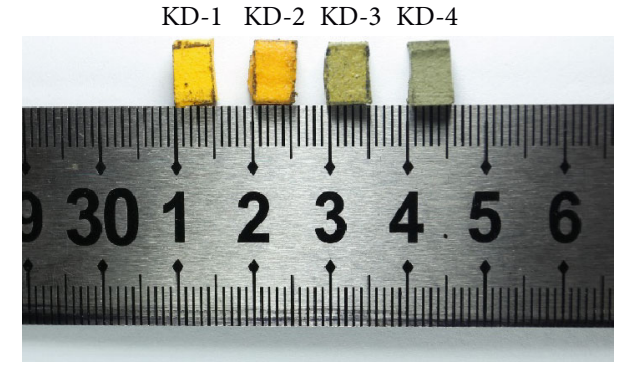

FIGURE 1: NEPE propellants adopted in the experiment.

imental study on the ignition process of NEPE propellants. The influence of the energy density, ingredients, and the grain size distribution on the ignition delay time, the ignition temperature, and the ignition energy were studied. The results are helpful to reveal the ignition mechanism of NEPE propellants and to find out the influential factors during the ignition process. Also, it provides fundamental information for the investigation and application of NEPE propellants.

\section{Experimental Method}

2.1. Sample Preparation. Figure 1 shows four kinds of NEPE propellants used in the experimental campaign, numbered from KD-1 to KD-4. The difference of components and grain size distribution causes their different colors. Samples adopted in this experiment were typically $5 \mathrm{~mm} \times 5 \mathrm{~mm} \times 7 \mathrm{~mm}$ rectangular bars. To obtain end burning, we dissolved polyvinyl butyral (PVB) in pure ethyl alcohol by heating and stirring and then coated samples with this mixture as fire retardant. This makes the experimental phenomena clearer and easier to be observed. Table 1 gives information of ingredients, weight mixture ratios, and grain sizes of four kinds of tested NEPE propellants. The binder is made of polyethylene glycol (PEG) (25\%) and plasticizer (75\%), and the plasticizer is composed of nitroglycerin (NG) $(50 \%)$ and butanetriol trinitrate (BTTN) (50\%).

2.2. Experimental Apparatus. The schematic diagram of the experimental apparatus is shown in Figure 2. It consists of a $\mathrm{CO}_{2}$ laser ignition system, a high-speed photography system, and a temperature measurement system. Since the sample is not heavy, it can be held by the tungsten-rhenium thermocouple with the uncoated ignition surface facing the igniter without touching any wall surface, which decreases the heat transfer between the sample and the platform during the ignition process. The thermocouple is embedded in the sample with the measurement point underneath the surface. All tests were conducted in air under ambient temperature and pressure.

Since the LED light and the $\mathrm{CO}_{2}$ laser igniter are controlled by the same signal generator, the LED light is regarded as a signal to indicate the moment when the igniter starts working. The high-speed camera was positioned in the right front of the ignition surface to observe the ignition process and to measure the ignition delay time. The background brightness was adjusted by a xenon lamp. All kinds of NEPE 
TABLE 1: Ingredients, weight mixture ratio, and grain size of tested NEPE propellants.

\begin{tabular}{|c|c|c|c|c|c|c|c|}
\hline Propellant name & $\begin{array}{c}\mathrm{AP}-1 / \% \\
(130 \mu \mathrm{m})\end{array}$ & $\begin{array}{l}\mathrm{AP}-2 / \% \\
(13 \mu \mathrm{m})\end{array}$ & $\begin{array}{c}\mathrm{HMX}-1 / \% \\
(86 \mu \mathrm{m})\end{array}$ & $\begin{array}{c}\mathrm{HMX}-2 / \% \\
(12 \mu \mathrm{m})\end{array}$ & $\begin{array}{c}\mathrm{Al}-1 / \% \\
(28 \mu \mathrm{m})\end{array}$ & $\begin{array}{l}\mathrm{Al}-2 / \% \\
(3 \mu \mathrm{m})\end{array}$ & $\begin{array}{c}\text { Binder } \\
(\%)\end{array}$ \\
\hline KD-1 & 10 & 10 & 48 & 1 & 1 & 1 & 32 \\
\hline $\mathrm{KD}-2$ & 20 & 1 & 24 & 24 & 1 & 1 & 32 \\
\hline KD-3 & 8 & 8 & 20 & 20 & 18 & 1 & 26 \\
\hline $\mathrm{KD}-4$ & 16 & 1 & 40 & 1 & 9 & 9 & 26 \\
\hline
\end{tabular}

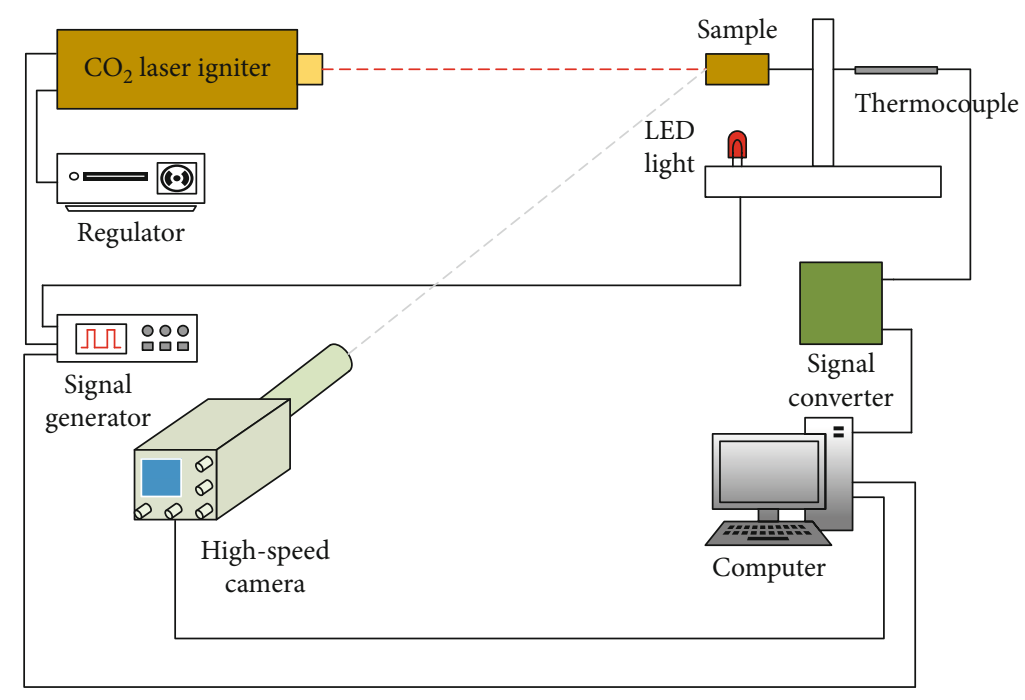

Figure 2: The schematic of the experimental setup.

propellant were tested five times under each condition to ensure the repeatability and accuracy of experimental results.

The $\mathrm{CO}_{2}$ laser ignition system consists of a $\mathrm{CO}_{2}$ laser igniter, a signal generator, and a control panel. The maximum power of the igniter is $200 \mathrm{~W}$ with the laser wavelength being $10.6 \mu \mathrm{m}$ and the laser focus radius being $0.5 \mathrm{~mm}$. Both the laser power and the irradiation time are adjustable. In this work, the laser irradiation time is $1 \mathrm{~s}$, which is much shorter than the time needed for the complete combustion of the sample.

High-speed photography system was adopted to observe and record the ignition process with high resolution. It consists of a high-speed camera, a lens set, and a computer. Two kinds of lenses were used in the experiment, including a zoom microscopic lens and a prime macro lens. The microscopic lens was used to observe the ignition at a whole sight, and the macro lens was used to observe the changes of surface morphology during the ignition process under strong background light provided by xenon lamp. In this paper, the collection frequencies are, respectively, $1000 \mathrm{fps}$ for zoom microscopic lens and $500 \mathrm{fps}$ for prime macro lens.

Temperature measuring system consists of a tungstenrhenium thermocouple, a signal converter, and a computer. The thermocouple has a filament diameter of $0.2 \mathrm{~mm}$ and a contact diameter of $0.5 \mathrm{~mm}$. The measurement ability ranges from 0 to 2300 degree centigrade, and the measurement error limit is $5 \%$. The data is displayed and recorded in real time with the collection frequency of $20 \mathrm{~Hz}$.

\subsection{Objective Parameters}

2.3.1. Ignition Delay Time. The LED light went off when the igniter began to work, and this time instant was regarded as the initial instant $t_{0}$. The time instant at which the first visible flame appeared was $t_{1}$. Then, the ignition delay time can be obtained as follows:

$$
t_{\text {ig }}=t_{1}-t_{0} .
$$

2.3.2. Ignition Temperature. The temperature behavior during the ignition process was recorded. After smoothing and fitting the original temperature data, we took a derivation of the temperature to acquire the first derivative of temperature versus time. The temperature of the peak point on the first derivative curve, which is caused by the abrupt change of the thermal conductivity, was regarded as the ignition temperature. Figure 3 shows the temperature curve and its first derivative curve of one test of KD-2. The temperature value when the first peak in the first derivative curve of temperature appears can be regarded as the temperature when the propellant surface vaporizes and thermally decomposes. Temperature increases sharply on the highest peak point, and the maximum heating rate can be hundreds of degrees per second, which makes it difficult to gain the accurate ignition temperature because of the limited response frequency of the thermocouple. The ignition temperatures we obtained after many tests were within a certain temperature range, and 


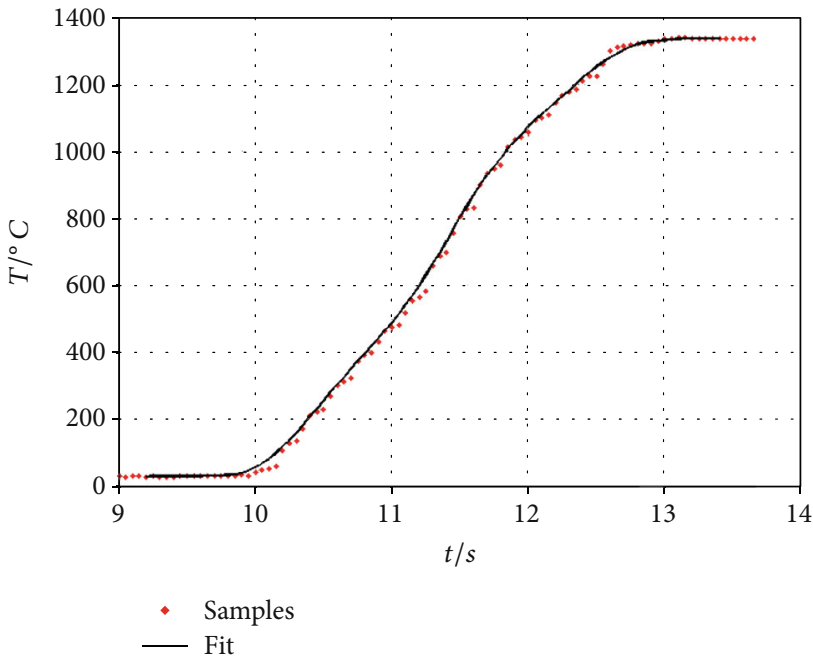

(a)

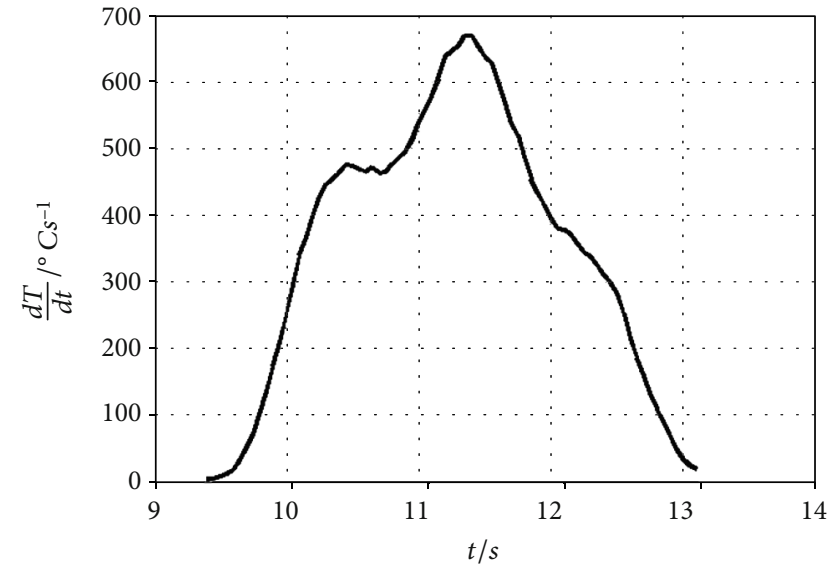

(b)

Figure 3: Temperature curve and its first derivative curve of KD-2. (a) Temperature curve. (b) First derivative curve of temperature.

their average value was regarded as the ignition temperature in this paper.

2.3.3. Ignition Energy. Although all the laser energy is put on the sample surface, it cannot be totally used for the ignition process. The ignition energy is defined as the energy stored in the sample up to ignition $[26,27]$ and can be calculated as

$$
E_{\text {ig }}=\int_{t=0}^{t_{\text {ig }}}\left[\alpha I_{0}-Q_{\text {conv }}-Q_{\text {emiss }}-\frac{\Delta H_{\text {melt }}}{\Delta t_{\text {melt }}}\right] \mathrm{d} t
$$

where $t_{\mathrm{ig}}$ is the ignition time, $\alpha$ is the sample radiative absorptivity, $I_{0}$ is the emitted laser power, $Q_{\text {conv }} \mathrm{d} t$ is the heat loss by convection, $Q_{\text {emiss }} \mathrm{d} t$ is the heat loss by radiation, $\Delta$ $H_{\text {melt }}$ is the latent heat of fusion, and $\Delta t_{\text {melt }}$ is the melting time. It means that not all the laser energy can be absorbed by the sample. Apart from the effective energy used for ignition, convection, radiation, and the melting process will all cause energy loss in this process.

In this paper, we only make a qualitative analysis of the ignition power for the complexity of the energy change on the ignition surface. The energy loaded by the igniter on the ignition surface during the ignition process was regarded as the ignition energy, namely $W_{\text {sp }}$. It is calculated as follows:

$$
W_{\mathrm{sp}}=I_{0} t_{\mathrm{ig}}
$$

where $I_{0}$ is the power of the igniter and $t_{\mathrm{ig}}$ is the ignition delay time.

\section{Results and Discussion}

3.1. Ignition Process of Nonaluminized NEPE Propellants. Figure 4 shows the ignition process of KD-1 sample under a loaded energy density of $56.02 \mathrm{~W} / \mathrm{mm}^{2}$ recorded by the high-speed camera and the zoom microscopic lens. Accord- ing to the transition of the grain surface, several key steps can be d4istinguished as follows.

(a) The LED light gave out light before the test and extinguished when the igniter began to work. The moment that the LED light extinguished was regarded as the initial moment, namely $t=0$

(b) At the instant of $t=0.067 \mathrm{~s}$, gas began to be observed to escape from the surface, which means the propellant began to gasify, and this instant was regarded as the first-gasification instant. During the period from beginning instant to first-gasification instant, the laser kept heating the sample surface, and the gas began to escape only after the surface reached a certain temperature. After the first-gasification instant, the gasification area kept expanding with heat accumulating on the surface and more gas escaped from the surface, as Figure 4(c) shows

(c) Then, at the instant of $t=0.095 \mathrm{~s}$, the first visible flame appeared, and this instant was called the first-flame instant. The sample could keep stable combustion since the laser energy was not removed from the surface

(d) The stable flame appeared at $t=0.179 \mathrm{~s}$, and this instant was called the ignition instant.

The period from the first-flame instant to ignition instant was called the active preignition stage. When the laser was switched off in this stage, the reaction could not continue, and there was no stable secondary flame. The period from the initial instant to ignition instant is defined as the ignition delay time. The ignition process can be divided into three stages according to the experimental evidence, and the time steps are first-gasification instant, first-flame instant, and ignition delay instant, respectively. $\mathrm{KD}-2, \mathrm{KD}-3$, and $\mathrm{KD}-4$ also have the same ignition stages and the same performance at active preignition stage as $\mathrm{KD}-1$. 


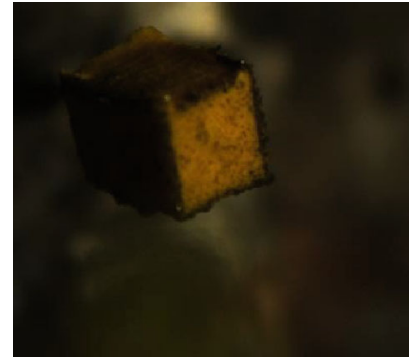

(a)

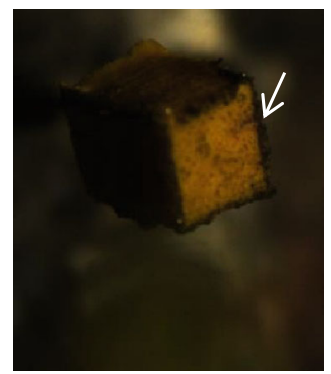

(d)

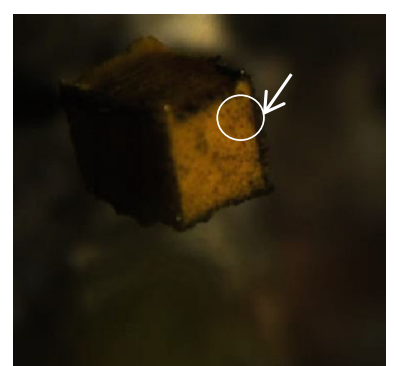

(b)

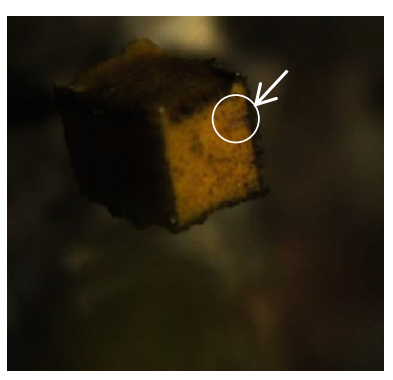

(c)

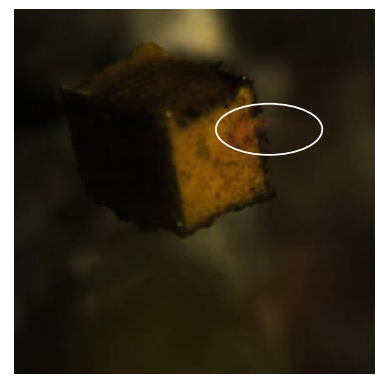

(e)

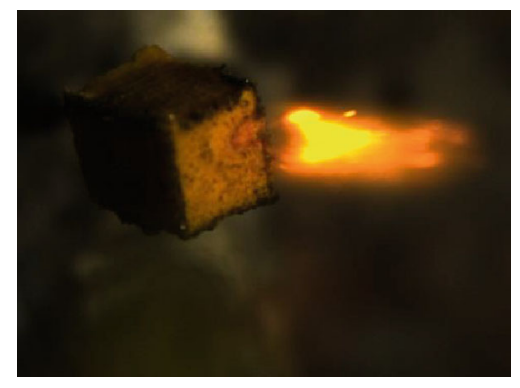

(f)

FIGURE 4: The ignition process of KD-1. (a) $t=0$, initial instant. (b) $t=0.067 \mathrm{~s}$, first-gasification instant. (c) $t=0.085 \mathrm{~s}$, gasification area expanding. (d) $t=0.095 \mathrm{~s}$, first-flame instant. (e) $t=0.166 \mathrm{~s}$, active preignition stage. (f) $t=0.179 \mathrm{~s}$, ignition instant.

The ignition process of KD-2 sample under the same condition recorded by the prime macro lens is illustrated in Figure 5. The liquefaction and gasification process can be observed more clearly. But the first visible flame and the stable flame cannot be observed clearly because of the excessively strong background light. As a result, only the first two stages before the appearance of the flame were analyzed in this part.

After the initial instant, liquefaction and gasification appeared successively within a short time interval. Under the continuous impingement of the laser, the gasification area kept expanding, and the liquefaction area between the gasification area and the unreacted area was relatively small. Before the appearance of the flame, some smallscale exothermic reactions of partial pyrolysis gas happened, and some light spots appeared in the gasification area. When the energy accumulated on the surface was enough, the flame appeared in the gasification area. Meanwhile, the gasification area spread more quickly under the dual effect of the laser radiation and the exothermic reaction in the gasification area.

3.2. Ignition Process of Aluminized NEPE Propellants. The flames of aluminized NEPE propellants during the ignition process are shown in Figure 6. These figures show that the ignition processes of aluminized and nonaluminized NEPE propellants are basically similar. For aluminized NEPE propellants, the ignition process can also be divided into three stages. The only difference is their flames containing many bright particles. Since the flame of aluminum particle is much brighter compared with other components, the aluminized NEPE propellants have much brighter flames.

Figure 7 shows the behavior of aluminum particles on the surface of KD-3 and KD-4 during ignition and combustion.
It can be seen that the aluminum particles (all $28 \mu \mathrm{m}$ ) in KD-3 firstly aggregate on the surface. After that, the aggregated aluminum particles escape from the surface under the effect of the gas generated by gasification and thermal decomposition and start burning in the gas phase. However, most of the aluminum particles in KD-4 (containing $28 \mu \mathrm{m}$ and $3 \mu \mathrm{m}$ aluminum particles) start burning just on the sample surface almost without aggregation and then escape from the surface quickly.

3.3. Effect of Laser Energy Density on Ignition. During the experiment, we found that even continuous laser cannot ignite the sample when the laser energy density is lower than $43.29 \mathrm{~W} / \mathrm{mm}^{2}$, which proves the existence of an ignition energy threshold in the ignition process of NEPE propellants.

Figure 8 shows the dependency of ignition delay time on energy density for different NEPE propellant samples. To ensure the data reliable and repeatable, five good videos were recorded to obtain the average ignition delay time for each interested energy density. When the energy density is high enough, the ignition delay time tends to be stable. The experimental results also show an approximate negative exponent relation between the ignition delay time and the energy density. The increase of energy density makes the surface temperature increase more quickly and the liquifying, gasification, and thermal decomposition happen more rapidly, which lead to the reduction of the ignition delay time. When the energy density is high enough, the rates of liquifying, gasification, and thermal decomposition reach saturated values and keep approximately stable. After that, the increase of energy density almost causes no effect on the ignition delay time.

The ignition energy values that different propellants need under different energy density conditions are obtained based 


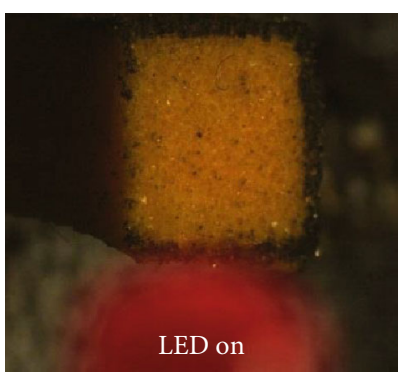

(a)

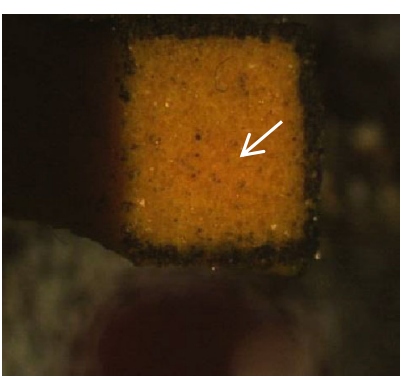

(c)

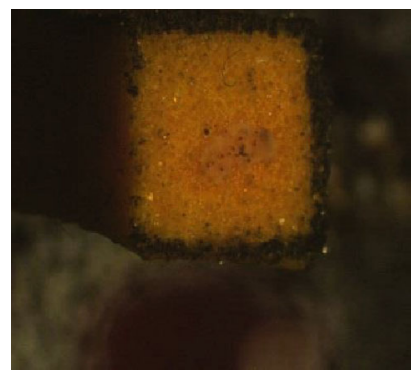

(e)

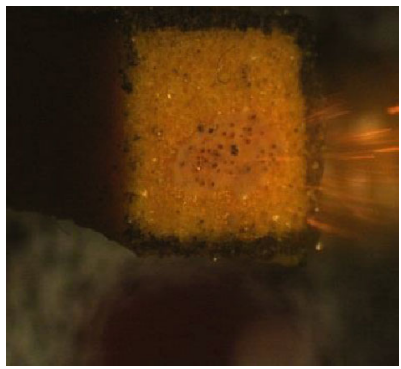

(g)

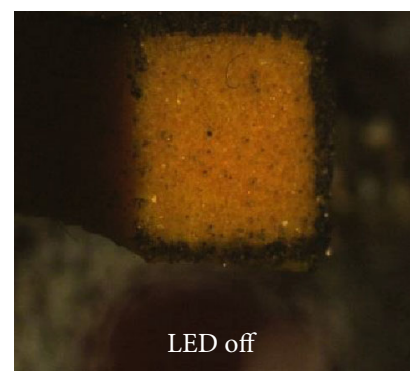

(b)

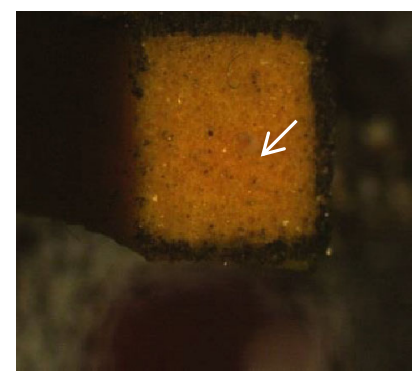

(d)

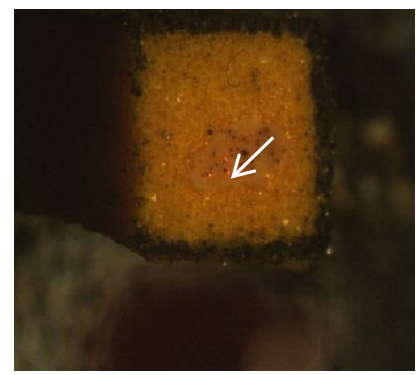

(f)

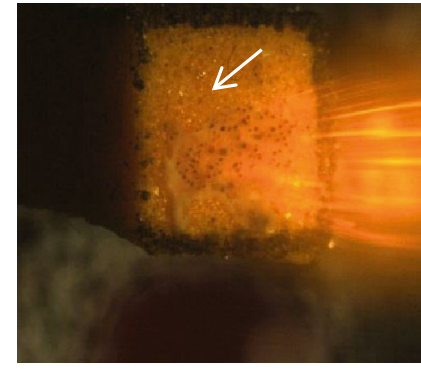

(h)

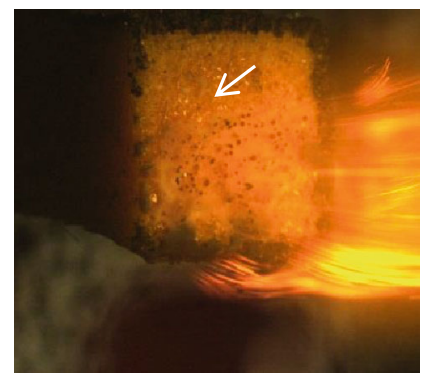

(i)

FIGURE 5: Ignition process of KD-2 observed by the prime macro lens. (a) Before the test. (b) Test began. (c) Liquefaction began. (d) Gasification began. (e) Expansion of gasification area. (f) Light spots appeared in the gasification area. (g) Flame appeared. (h) Liquefaction of unburned area. (i) Gasification of unburned area. 


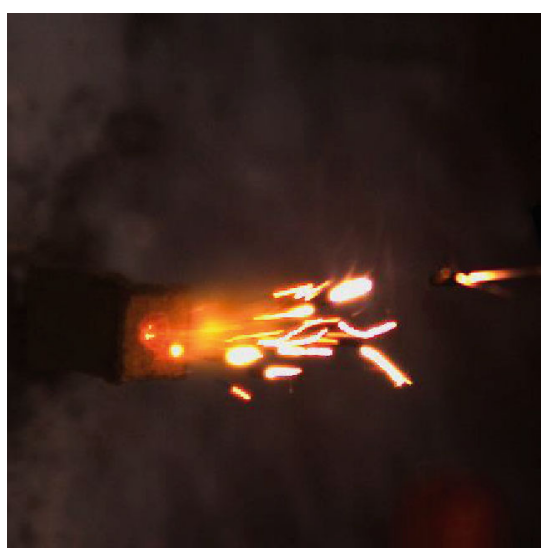

(a)

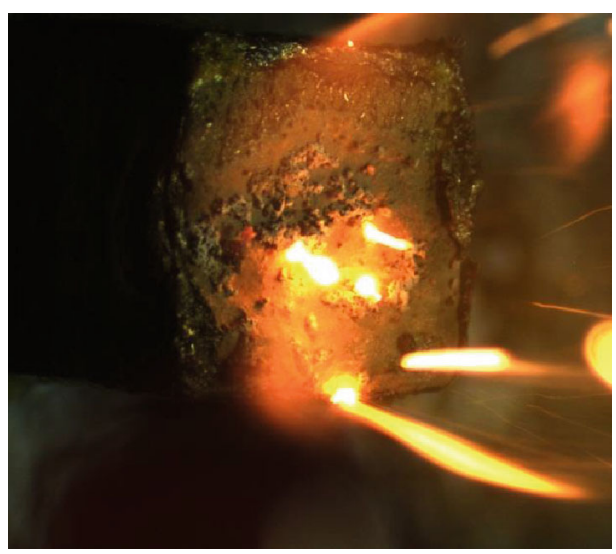

(b)

FIGURE 6: Flames of aluminized NEPE propellants. (a) Flame of KD-3 observed by the zoom microscopic lens. (b) Flame of KD-4 observed by the prime macro lens.

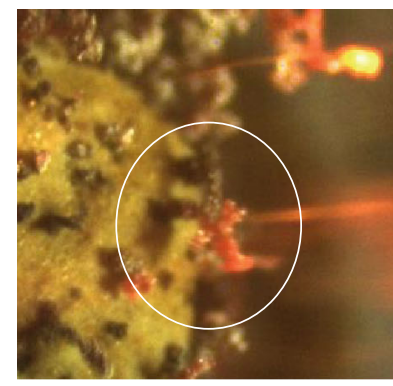

(1) $t=3.234 \mathrm{~s}$

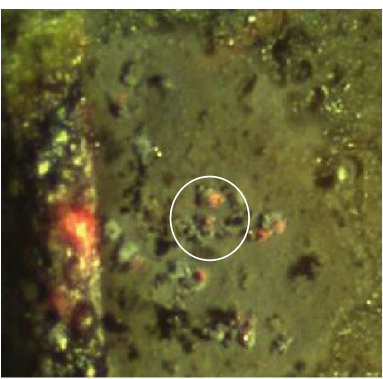

(1) $t=0.168 \mathrm{~s}$

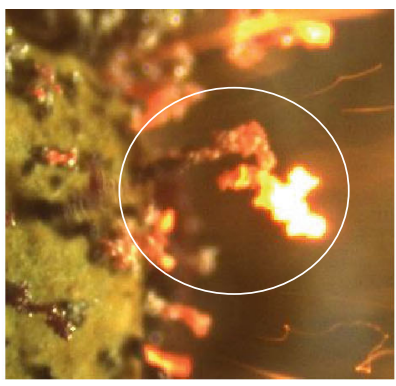

(2) $t=3.334 \mathrm{~s}$

(a)

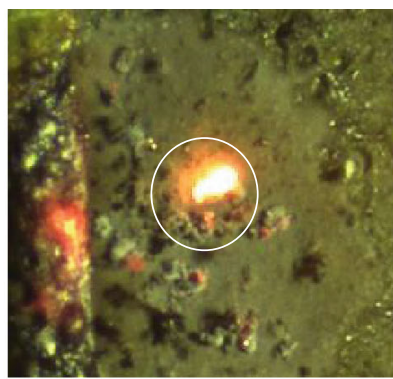

(2) $t=0.17 \mathrm{~s}$

(b)

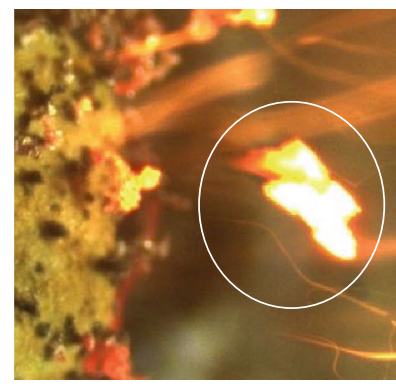

(3) $t=3.414 \mathrm{~s}$

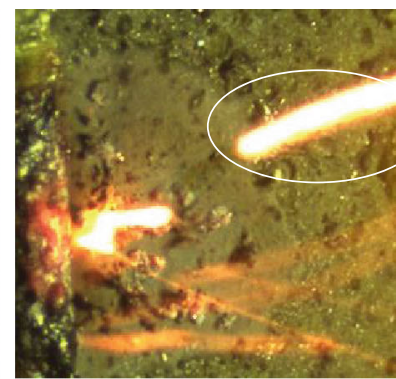

(3) $t=0.174 \mathrm{~s}$

FIgURE 7: Difference behaviors of aluminum of KD-3 and KD-4. (a) KD-3. (b) KD-4.

on Eq. (3). Figure 9 indicates that the energy needed for ignition decreases with the increase of energy density for both nonaluminized NEPE propellants and aluminized NEPE propellants. When the energy density is high enough, the energy needed for ignition is almost unchanged, which is regarded as the minimum energy the propellant needs for ignition.

3.4. Effect of Ingredients and Grain Size on Ignition. Figure 8 indicates that the ignition delay time of KD-1 was shorter than that of KD-2. According to Table 1, KD-1 and KD-2 have the same ingredients, but different grain size distribution. KD-1 has bimodal AP distribution containing AP with smaller grain size while KD-2 has bimodal HMX distribution containing HMX with smaller grain size. According to existing studies, it takes a little time for AP from gasification to ignition under heat flow. The decomposition and homogeneous diffusion can happen more easily for AP particle with smaller grain size because of its larger surface area. As a result, the exothermic gas-phase reaction happens more rapidly. But for HMX, there is an obvious ignition delay and a go/no-go line. Only when the go/no-go line has been reached 


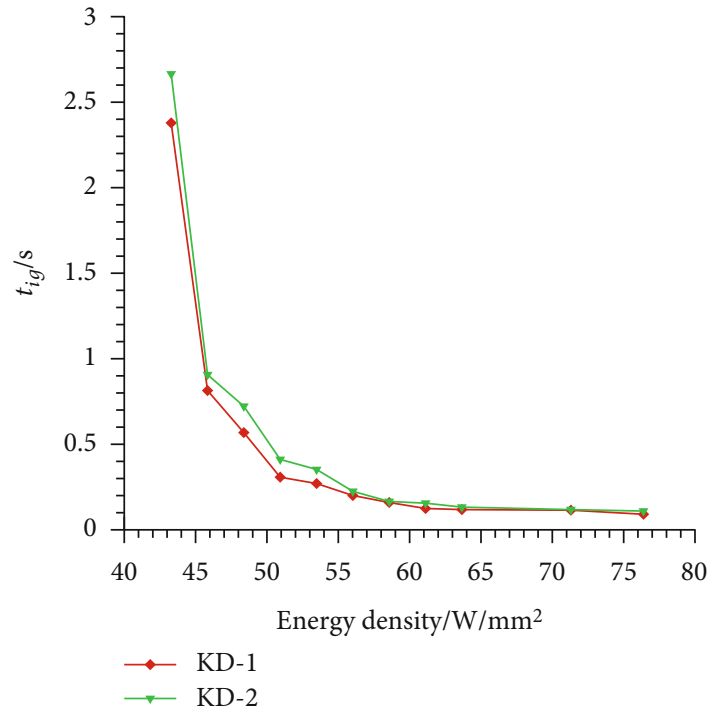

(a)

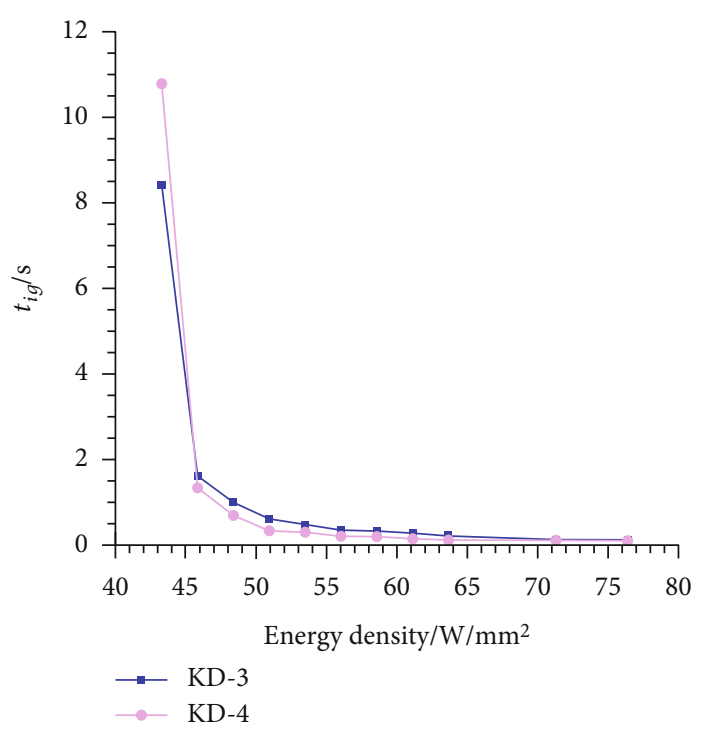

(b)

FIgURE 8: Ignition delay time versus energy density. (a) Nonaluminized NEPE. (b) Aluminized NEPE.

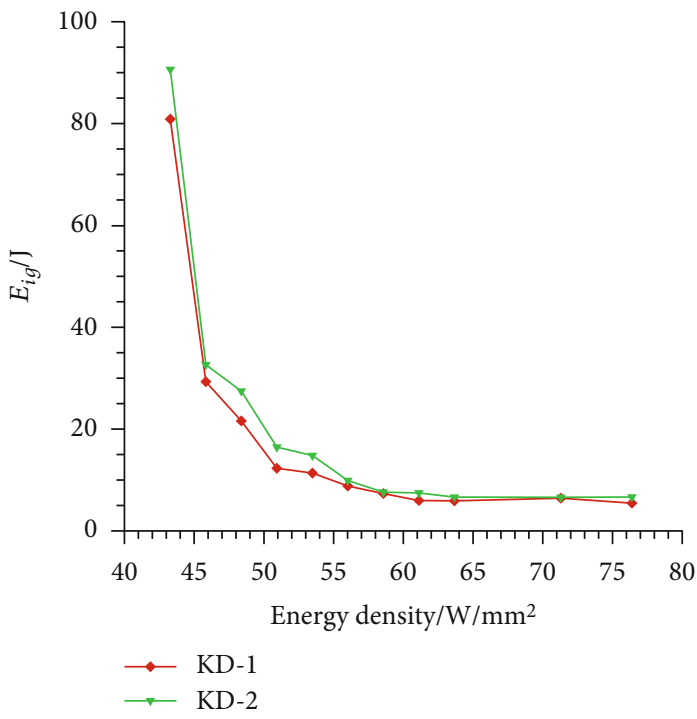

(a)

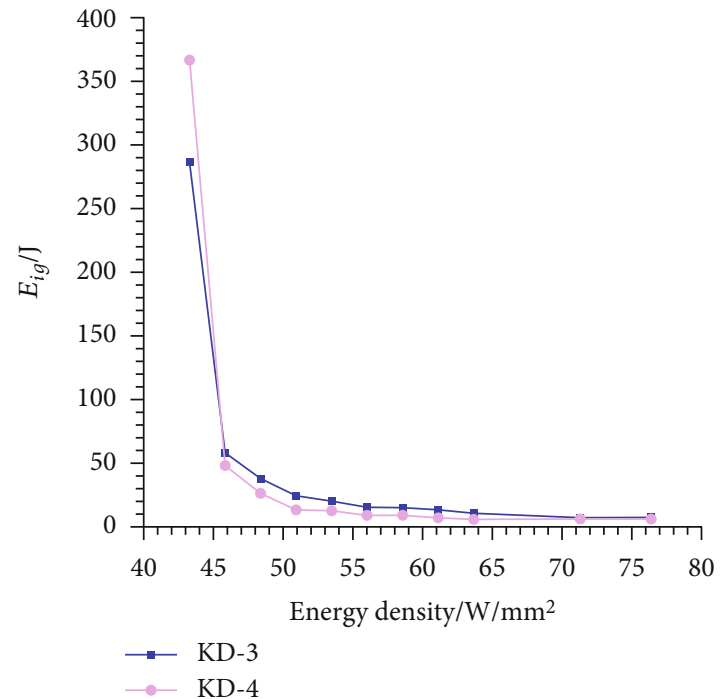

(b)

FIgURE 9: Ignition energy versus energy density. (a) Nonaluminized NEPE. (b) Aluminized NEPE.

can HMX maintain stable combustion with the removal of external energy. For HMX particles, the smaller the grain size is, the faster the melting and decomposition is $[28,29]$. In summary, for both AP and HMX, the decrease of grain size makes the combustion easier and the ignition delay time shorter. Experimental results suggest that for oxidizer, the grain size of AP has severer effect on the ignition delay time than the grain size of HMX.

Figure 8 also indicates that the ignition delay time of KD4 is shorter than that of KD-3. According to Table 1, KD-3 and KD-4 have the same ingredients but different grain size distributions. KD-3 contains oxidizer with smaller grain size while KD-4 contains aluminum with smaller grain size. The ignition energy of aluminum particles can be obtained by the following equation [30]:

$$
E_{\mathrm{Al}}=\int_{T_{0}}^{T_{\mathrm{Al}, m}} m_{\mathrm{Al}, m} \cdot C_{\mathrm{P}, \mathrm{Al}} \mathrm{d} T+m_{\mathrm{Al}} \cdot \Delta H_{\mathrm{Al}}+\int_{T_{\mathrm{Al}, m}}^{T_{\mathrm{Al}_{2} \mathrm{O}_{3}}} m_{\mathrm{Al}} \cdot C_{\mathrm{P}, \mathrm{Al}} \mathrm{d} T .
$$

In Eq. (4), $m_{\mathrm{Al}, m}$ is the mass of aluminum when the temperature increase from $T_{0}$ to $T_{\mathrm{Al}, m}$, which is the melting point. $m_{\mathrm{Al}}$ is the mass of the aluminum particle. $\Delta H_{\mathrm{Al}}$ is the melting heat of aluminum. The equation suggests that the 
TABLE 2: Ignition temperature of NEPE propellant under different energy density $\left({ }^{\circ} \mathrm{C}\right)$.

\begin{tabular}{lcccc}
\hline & $45.84 \mathrm{~W} / \mathrm{mm}^{2}$ & $50.93 \mathrm{~W} / \mathrm{mm}^{2}$ & $56.02 \mathrm{~W} / \mathrm{mm}^{2}$ & $63.66 \mathrm{~W} / \mathrm{mm}^{2}$ \\
\hline $\mathrm{KD}-1$ & 446.0 & 422.5 & 449.7 & 462.1 \\
$\mathrm{KD}-2$ & 532.1 & 514.4 & 519.9 & 565.3 \\
$\mathrm{KD}-3$ & 539.7 & 509.5 & 496.4 & 522.9 \\
$\mathrm{KD}-4$ & 543.9 & 593.9 & 560.1 & 569.1 \\
\hline
\end{tabular}

smaller the particle size of aluminum is, the smaller the ignition energy is, and the shorter the ignition delay time is under the same energy density. Experimental results suggest that the decrease of grain size of aluminum can decrease the ignition delay time more effectively than that the oxidizer can do, which suggests that the grain size of aluminum has more effect on the ignition delay time than the grain size of the oxidizer.

3.5. Ignition Temperature. Table 2 shows the ignition temperature of NEPE propellants under different energy density in air calculated by the method given above. Results indicate that the ignition temperature is independent on energy density but greatly affected by the ingredient and the grain size distribution of components of the propellant. The ignition temperature of KD-1 is lower than that of KD-2. Figure 8 (a) shows that the ignition delay time of $\mathrm{KD}-1$ is shorter than that of KD-2. These results can be explained by assuming that for nonaluminized NEPE propellants, the decomposition of AP dominates the ignition process. Therefore, the lower decomposition temperature of KD-1 with finer AP causes the decrease of ignition delay time. Consequently, the ignition delay time and the ignition temperature can be adjusted more effectively through adjusting the grain size distribution of AP.

A certain increase of the ignition temperature can be seen after the addition of aluminum particles. Results indicate that the ignition temperature of KD-4 is a little higher than that of the KD-3, but the difference is not as obvious as that between KD-1 and KD-2. Figure 7(b) shows that the ignition delay time of $\mathrm{KD}-3$ is longer than that of $\mathrm{KD}-4$. One reason for this is that although the oxidizer with smaller grain size in KD-3 can decrease its decomposition temperature and the ignition delay time, the aluminum particles with smaller grain size in KD-4 can make preheating, oxide rupture, and the melting process absorb less energy from the surface and then make the ignition easier. Besides, the combustion of aluminum particles in gas reaction zone can release much heat. The smaller the grain size is, the more vigorous the combustion can be, followed by a higher burning rate and more energy provided for the combustion surface, which would further promote the ignition. It appears that aluminum particles played a leading role in the ignition process compared with the oxidizer. As a result, for aluminized NEPE propellant, the ignition delay time and the ignition temperature can be adjusted more effectively through adjusting the grain size distribution of aluminum particles compared with the oxidizer.

\section{Analysis and Conclusions}

An experimental investigation was conducted to study the effect of the energy density, ingredients, and the grain size distribution of propellant on the ignition process of NEPE propellants. The following shows the analysis of the experimental results and the conclusions.

(a) Ignition processes of both nonaluminized and aluminized NEPE propellants consist three stages. The first stage is from the initial instant to the first-gasification instant, and in this stage, the NEPE propellant absorbed heat, and then liquefaction and gasification happen. The second stage ranges from the first-gasification to the first-flame instant. In this stage, the thermal decomposition and the exothermic reaction in the gas phase on the surface cause the first-flame emission. The third stage, the active preignition stage, ranges from the firstflame instant to the ignition delay instant

(b) An ignition energy threshold exists in the ignition process of NEPE propellant. When the energy density is lower than that, even continuous energy impingement cannot make the ignition process happen. Both the ignition delay time and the ignition energy decrease with the increase of energy density. However, when the laser energy density is high enough, both the ignition delay time and the ignition energy tend to be stable

(c) The effect of grain size on the ignition delay time seems to have the following order: aluminum $>$ AP $>$ HMX. The ignition temperature is dependent on the ingredients and the grain size contribution but shows a less dependence on the laser energy density. The effect of grain size of particles on the ignition temperature seems to have the following order: aluminum $>$ AP $>$ HMX. Consequently, the grain size of aluminum particle is more dominant in the ignition process than that of the oxidizer, while for oxidizer, the grain size of AP is more dominant than that of HMX. After the addition of aluminum particles, the ignition temperature increases obviously. This suggests that the effect of immense heat produced during the combustion process in the gas-phase reaction zone on the combustion surface of the sample cannot be ignored.

\section{Data Availability}

The experimental data used to support the findings of this study are available from the corresponding author upon request. 


\section{Conflicts of Interest}

The authors declare that there is no conflict of interest regarding the publication of this paper.

\section{Acknowledgments}

The authors would like to express their thanks for the support from the National Natural Science Foundation of China (No. 11572349) and Natural Science Foundation of Hunan Province (No. 2018JJ3606).

\section{References}

[1] L. T. De Luca, T. Shimada, V. P. Sinditskii, and M. Calabro, Chemical Rocket Propulsion - a Comprehensive Survey of Energetic Materials, 2016.

[2] H. Tan, The Chemistry and Technology of Solid Rocket Propellant, Beijing Institute of Technology Press, Beijing, 2015.

[3] Y.-J. Luo and J.-R. Liu, "Research progress of high energy solid propellant," Energetic Materials-Chengdu, vol. 15, no. 4, p. 407, 2007.

[4] A. Davenas, Solid rocket propulsion technology, Astronautic Publishing House, Beijing, 1997.

[5] H. X. Hao, Q. Pei, F. Q. Zhao, and S. W. Li, "Summarization of laser ignition characteristics of solid propellants," Chinese Journal of Energetic Materials, vol. 17, pp. 491-498, 2009.

[6] V. N. Viliunov and V. E. Zarko, Ignition of solids, Elsevier : Distribution for the U.S.A. and Canada, Elsevier Science Publishing Co, New York, 1989.

[7] A. Ali, S. Son, R. Sander, B. Asay, and M. Brewster, "lgnition Dynamics of High Explosives," in 37th AIAA Aerospace Sciences Meeting and Exhibit, Reno, NV, 1999.

[8] M. Weinrotter, H. Kopecek, E. Wintner, M. Lackner, and F. Winter, "Application of laser ignition to hydrogen-air mixtures at high pressures," International Journal of Hydrogen Energy, vol. 30, no. 3, pp. 319-326, 2005.

[9] T. X. Phuoc, "Laser-induced spark ignition fundamental and applications," Optics and Lasers in Engineering, vol. 44, no. 5, pp. 351-397, 2006.

[10] A. Ulas and K. K. Kuo, "Laser-induced ignition of solid propellants for gas generators," Fuel, vol. 87, no. 6, pp. 639-646, 2008.

[11] A. N. Ali, M. M. Sandstrom, D. M. Oschwald, K. M. Moore, and S. F. Son, "Laser ignition of DAAF, DHT and DAATO(3.5)," Propellants Explosives Pyrotechnics, vol. 30, no. 5, pp. 351-355, 2005.

[12] E. M. Hunt and M. L. Pantoya, "Ignition dynamics and activation energies of metallic thermites: from nano- to micron-scale particulate composites," Journal of Applied Physics, vol. 98, no. 3, p. 034909, 2005.

[13] C. Zanotti, P. Giuliani, A. Terrosu, S. Gennari, and F. Maglia, "Porous Ni-Ti ignition and combustion synthesis," Intermetallics, vol. 15, no. 3, pp. 404-412, 2007.

[14] M. Monagheddu, N. Bertolino, P. Giuliani, C. Zanotti, and U. A. Tamburini, "Ignition phenomena in combustion synthesis: an experimental methodology," Journal of Applied Physics, vol. 92, no. 1, pp. 594-599, 2002.

[15] V. Medvedev, V. Tsipilev, and E. Forat, "Effect of ammonium perchlorate and aluminum composition density on characteristics of laser ignition," Propellants, Explosives, Pyrotechnics, vol. 43, pp. 122-125, 2017.
[16] V. Medvedev, V. Tsipilev, A. Reshetov, and A. Ilyin, "Conditions of millisecond laser ignition and thermostability for ammonium perchlorate/aluminum mixtures," Propellants Explosives Pyrotechnics, vol. 42, no. 3, pp. 243-246, 2017.

[17] A. R. Demko, C. Dillier, T. Sammet, E. L. Petersen, D. L. Reid, and S. Seal, "Ignition delay times of composite solid propellants using novel nano-additive catalysts," Journal of Propulsion and Power, vol. 34, no. 5, pp. 1285-1296, 2018.

[18] J. Sivan and Y. Haas, "Laser ignition of various pyrotechnic mixtures - an experimental study," Propellants Explosives Pyrotechnics, vol. 40, no. 5, pp. 755-758, 2015.

[19] Y. Feng, Z. Xia, L. Huang, and X. Yan, "Experimental investigation on the combustion characteristics of aluminum in air," Acta Astronautica, vol. 129, pp. 1-7, 2016.

[20] J. Ehrhardt, L. Courty, P. Gillard, and B. Baschung, "Experimental study of pyrolysis and laser ignition of lowvulnerability propellants based on RDX," Molecules, vol. 25, no. 10, p. 2276, 2020.

[21] S. F. Li, H. L. Niu, and G. C. Zhang, "Laser ignition of NEPE propellant," Journal of Propulsion Technology, vol. 23, no. 2, pp. 172-175, 2002.

[22] W. A. Hong-mei, C. H. Xiong, and Z. H. Chao, "Study on ignition and combustion characteristics of NEPE propellant under laser irradiation," Journal of Propulsion Technology, vol. 8, pp. 1262-1267, 2015.

[23] H. S. Xiang, X. Chen, C. S. Zhou, and H. J. Lai, "Effect of oxygen content in environment gas on the laser ignition process of NEPE propellant," Chinese Journal of Explosives \& Propellants, vol. 39 , no. 3 , pp. 75-79, 2016

[24] G. Q. Zhu, X. Chen, C. S. Zhou, and Q. J. Wu, "Study on laser ignition characteristics of NEPE propellant," Advanced Materials Research, vol. 549, no. 2, pp. 1037-1040, 2012.

[25] L.-B. Li, X. Chen, C. S. Zhou, M. Zhu, and O. Musa, "Experimental investigation on laser ignition and combustion characteristics of NEPE propellant," Propellants, Explosives, Pyrotechnics, vol. 42, no. 9, pp. 1095-1103, 2017.

[26] N. Bertolino, M. Monagheddu, A. Tacca, P. Giuliani, C. Zanotti, and U. A. Tamburini, "Ignition mechanism in combustion synthesis of $\mathrm{Ti}-\mathrm{Al}$ and $\mathrm{Ti}-\mathrm{Ni}$ systems," Intermetallics, vol. 11, no. 1, pp. 41-49, 2003.

[27] C. Milanese, F. Maglia, A. Tacca, U. Anselmi-Tamburini, C. Zanotti, and P. Giuliani, "Ignition and reaction mechanism of $\mathrm{Co}-\mathrm{Al}$ and $\mathrm{Nb}-\mathrm{Al}$ intermetallic compounds prepared by combustion synthesis," Journal of Alloys and Compounds, vol. 421, no. 1-2, pp. 156-162, 2006.

[28] T. L. Boggs, C. F. Price, A. I. Atwood, D. E. Zurn, and R. L. Derr, "The role of gas phase reactions in the deflagration-todetonation transition of high energy propellants," Dissertations \& Theses - Gradworks, vol. 104, no. 26, pp. 7496-7500, 1980.

[29] J. Zheng, L. Hou, and Z. Yang, "The progress and prospects of high energy propellants," Journal of Solid Rocket Technology, vol. 24, no. 1; ISSU 92, pp. 28-34, 2001.

[30] H. Wang, Study on Combustion Mechanism and Burning Performance of Composite Solid Propellants, Nanjing, Nanjing University of Science and Technology, 2015. 